\title{
Future climate changes under different scenarios and their effects on runoff in the upper Taohe River Basin
}

\author{
zhen wang ${ }^{1}$, Meixue Yang $^{2}$, xuejia wang ${ }^{3}$, lizhen cheng $^{3}$, guoning wan $^{3}$, and yongshang li $^{1}$ \\ ${ }^{1}$ Chinese Academy of Sciences Lanzhou Branch \\ ${ }^{2}$ Cold and Arid Regions Environmental and Engineering Research Institute \\ ${ }^{3}$ Chinese Academy of Sciences
}

February 2, 2021

\begin{abstract}
Climate changes may pose challenges to water management. Simulation and projection of climate-runoff processes through hydrological models are essential means to assess the impact of global climate change on runoff variations. This study focuses on the upper Taohe River Basin which is an important water sources for arid and semi-arid regions in Northwest China. In order to assess the impacts of environmental changes, outputs from a regional climate model and the SWAT hydrological model were used to analyze the future climate change scenarios to water resources quantitatively. The examined climate changes scenarios results showed that average annual temperature from 2020 to 2099 in this area exhibits a consistent warming trend with different warming rates, at rates of $0.10^{\circ} \mathrm{C} / 10 \mathrm{a}, 0.20^{\circ} \mathrm{C} / 10 \mathrm{a}$ and $0.54^{\circ} \mathrm{C} / 10 \mathrm{a}$ under RCP2.6, RCP4.5 and RCP8.5(Representative Concentration Pathways, RCPs), The value of precipitation experiences different trends under different emission scenarios. Under the RCP2.6, average precipitation would decrease at a rate of $3.69 \mathrm{~mm} / 10 \mathrm{a}$, while under the RCP4.5 and RCP8.5, it would increase at rates of $4.97 \mathrm{~mm} / 10 \mathrm{a}$ and $12.28 \mathrm{~mm} / 10 \mathrm{a}$, respectively. The calibration and validation results in three in-site observations (Luqu, Xiabagou and Minxian) in the upper Taohe River Basin showed that SWAT hydrological model is able to produce an acceptable simulation of runoff at monthly time-step. In response to future climate changes, projected runoff change would present different decreasing trends. Under RCP2.6, annual average runoff would experience a progress of fluctuating trend, with a rate of- $0.6 \times 108 \mathrm{~m} 3$ by 5 -year moving average method; Under the RCP4.5 and RCP8.5, annual average runoff would show steadily increasing trends, with rates of $0.23 \times 108 \mathrm{~m} 3$ and $0.16 \times 108 \mathrm{~m} 3$ by 5 -year moving average method. The total runoff in the future would prone to drought and flood disasters. Overall, this research results would provide a scientific reference for reginal water resources management on the long term.
\end{abstract}

\section{Hosted file}

Future climate changes under different scenarios and their effects on runoff in the upper Taohe River B available at https://authorea.com/users/393194/articles/506875-future-climate-changes-underdifferent-scenarios-and-their-effects-on-runoff-in-the-upper-taohe-river-basin 